\title{
Frequency of Firmicutes and Bacteroidetes in gut microbiota in obese and normal weight Egyptian children and adults
}

\author{
Nagwa Abdallah Ismail, Shadia H. Ragab, Abeer Abd ElBaky, Ashraf R.S. Shoeib, Yasser Alhosary, \\ Dina Fekry
}

Pediatrics Department, National Research Centre, Cairo, Egypt

Submitted: 21 June 2010

Accepted: 6 September 2010

Arch Med Sci 2011; 7, 3: 501-507

DOI: 10.5114/aoms.2011.23418

Copyright @ 2011 Termedia \& Banach

\begin{abstract}
Introduction: Obesity and associated metabolic disorders are a worldwide epidemic. Recent evidence suggests that the microbial community in the human intestine may play an important role in the pathogenesis of obesity. The aim of this study was to assess the differences in the composition of the intestinal microbiota between obese and normal weight Egyptian children and adults.

Material and methods: The study included 79 subjects among whom 51 were obese ( 23 children and 28 adults), and 28 were subjects of normal weight (17 children and 11 adults). Faecal samples were collected from all subjects. Total DNA was extracted from collected stool samples and submitted to conventional PCR for detection of Firmicutes and Bacteroidetes. All the studied group was subjected to clinical and anthropometric evaluation. Laboratory assessment of fasting glucose, high-sensitivity C-reactive protein (hsCRP) and lipid profile was performed.

Results: The proportions of the phyla Firmicutes and Bacteroidetes were statistically significantly increased in the obese group compared to the normal weight group ( $p<0.001, p=0.003$ respectively). The study also found a statistically significant positive trend for higher hsCRP in subjects with positive Firmicutes $(p=0.004)$. However, no associations were found between positive Bacteroidetes and hsCRP.

Conclusions: The results of this study indicate that obesity in Egyptian children and adults is associated with compositional changes in faecal microbiota with increase in the phyla Firmicutes and Bacteroidetes. This could be considered when developing strategies to control obesity and its associated diseases by modifying the gut microbiota.
\end{abstract}

Key words: obesity, gut microbiota, Firmicutes, Bacteroidetes, high-sensitivity C-reactive protein.

\section{Introduction}

Obesity represents one of the five major health risks in modern societies with a frequency of more than $20 \%$ of the population in developed countries [1]. As a consequence of the expected dramatic increase in obesity prevalence rates, life expectancy may start to decrease for the first time in recent history due to numerous co-morbid disorders [2, 3].

The intestinal flora has been recently proposed as an environmental factor involved in the control of body weight and energy homeostasis

\author{
Correspondence author: \\ Prof. Nagwa A. Ismail \\ Pediatrics Department \\ National Research Centre \\ Albhoss St \\ Cairo, Egypt \\ E-mail: \\ nagwa_abdallah@yahoo.com
}


[4-8]. The human intestine contains a large variety of microorganisms, consisting of at least 1014 bacterial cells and up to 500-1000 different species [9]. As a whole this represents overall more than 100 times the human genome $[9,10]$, and is called the "metagenome". Thus, the intestinal flora can be considered as an "exteriorized organ" which contributes to our homeostasis with multiple, highly diversified functions. Studies have shown that the gut microbiota is dominated by 2 bacterial phyla, the gram-negative Bacteroidetes and the grampositive, low GC\% Firmicutes [11, 12], with other phyla represented at subdominant levels including the Actinobacteria, Fusobacteria and Verrucomicrobia phyla [11]. Within these phyla the dominant bacterial groups include the Clostridium coccoides-Eubacterium rectale group, Clostridium leptum group (Firmicutes), Bacteroides-Prevotella species (Bacteroidetes), Bifidobacterium and Atopobium genera (both Actinobacteria) [13]. Firmicutes are in the class Bacillus [14], which is rare in the human or mouse gut microbiota; none is a member of the Clostridium XIV class, which contains the most abundant representatives of this division in the distal guts of mice and humans. Hence, the physiological contributions of Firmicutes to the intestinal ecosystem, and to fuel partitioning, are unclear [14].

Diet-induced and genetically obese mice (ob/ob or $d b / d b)$ showed a significant upregulation of expression of Toll-like receptors 1 to 9 in adipocytes and pre-adipocytes along with higher cytokine production upon stimulation [15]. In particular, it is known that Toll-like receptor 4 (TLR-4) can be activated by both lipopolysaccharide (LPS) and dietary saturated fatty acids inducing upregulation of common intracellular inflammatory pathways, such as JNK and NF- $\kappa$ B in adipocytes and macrophages, related to the induction of insulin resistance and increased adiposity [16]. Recently, metabolic endotoxaemia, characterized by an increase in serum LPS levels, has been demonstrated to be an inflammatory factor, causing body weight gain, insulin resistance, and diabetes in high-fat fed animal models [17-19].

C-reactive protein (CRP) is an acute-phase protein that is a sensitive marker for systemic inflammation. Several inflammation-related diseases such as respiratory disease, rheumatoid arthritis, diabetes mellitus, and cardiovascular disease have been associated with elevated CRP concentrations. Moreover, recent studies have reported a positive relation between body mass index and CRP concentrations [20-22]. In obesity, an elevated CRP level concentration is explained by increased interleukin- 6 expression in adipose tissue and its release into the peripheral circulation. The role of the gut microbiota in modulating plasma LPS levels, which triggers the inflammatory tone and the onset of obesity and type 2 diabetes, is under evaluation [23]. More studies are needed to unravel how changing gut microbiota impacts on the development of obesity and related metabolic alterations. The idea that gut microbial diversity is linked to obesity deserves exploration in humans, because it may yield new treatment strategies for this growing worldwide threat to our health.

The aim of this study was to assess the differences in the composition of the intestinal microbiota between obese and normal weight Egyptian children and adults by comparing the Firmicutes and Bacteroidetes frequency in the stool and its correlation with high-sensitivity C-reactive protein (hsCRP), as a marker of inflammation, and also the correlation with the amount of dietary fat and carbohydrate intake.

\section{Material and methods}

All subjects were recruited between September 2008 and December 2009 from outpatient clinics at the National Research Centre (NRC). Out of 120 subjects randomly chosen, only 79 were included in this study, among whom 51 were obese $(23$ children and 28 adults), and 28 were subjects of normal weight (17 children and 11 adults). Cases with hepatic disease, hypertension, asthma, infection, tumour, febrile conditions (or had febrile conditions within the previous 2 months), congestive heart failure, diseases affecting the gut microbiota, recent antibiotic intake and other acute inflammatory diseases were excluded from this study. Obesity in children and adults was considered as body mass index (BMI) $\geq 30 \mathrm{~kg} / \mathrm{m}^{2}$ and overweight as BMI $\geq 25 \mathrm{~kg} / \mathrm{m}^{2}$ and $<30 \mathrm{~kg} / \mathrm{m}^{2}$ [24]. Corresponding normative data for Egyptian children and adolescents were used. Overweight was defined as between the $90^{\text {th }}$ and $95^{\text {th }} \mathrm{BMI}$ percentiles and obesity as $>95^{\text {th }}$ percentile in both children and adolescents.

A detailed medical and family history was obtained from all subjects and a complete physical examination was performed, including anthropometric parameters (height, weight), fatness indices (BMI, standard deviation score-BMI - SDS-BMI, and basal blood pressure).

\section{Nutritional evaluation}

Twenty-four-hour dietary recalls for three successive days were done for all cases and were evaluated according to the food pyramid guidelines. Food frequency questionnaires (FFQs) ask about the usual frequency of consumption of a list of foods mainly to evaluate fat and carbohydrate intake.

Stool samples were collected from all subjects and were diluted as $20 \%$ using sterile EDTA (50 mM), 
then all samples were purified from stool deprise by centrifugation at $5000 \mathrm{rpm}$ for $10 \mathrm{~min}$ [25].

\section{DNA extraction}

DNA was extracted from diluted stool samples using Wizard Genomic DNA Purification Kit (Promega, Cat. No. A1120), according to the manufacturer's instructions, and extracted DNA was stored at $-20^{\circ} \mathrm{C}$ for detection of Bacteroidetes and Firmicutes by PCR $[25,26]$.

\section{Polymerase chain reaction}

\section{Oligonucleotide primers}

For amplification of selected DNA segments of Bacteroidetes and Firmicutes, two pairs of oligonucleotide primers were used as detected in stool samples using primers reported by Dick and Field, 2004 and Scupham et al., 2006, respectively $[25,27]$. The primer sequences were: BactFA ACGCTAGCTACAGGCTTAACA (Forward) and BactR ACGCTACTTGGCTGGTTCA (Reverse), for Bacteroidetes, and FirmF GCGTGAGTGAAGAAGT (Forward) and FirmR CTACGCTCCCTTTACAC (Reverse) for Firmicutes.

\section{PCR amplification}

Polymerase chain reaction amplification was carried out in $50 \mu \mathrm{l}$ reaction mixture containing $10 \mu$ l of DNA, $5 \mu$ l of $10 \times$ PCR buffer, $4 \mu$ l of $\mathrm{MgCl}_{2}$ (25 mM), $0.5 \mu \mathrm{l}(5 \mathrm{U} / \mu \mathrm{l})$ of Go Taq Flexi DNA Polymerase (Promega Cat. No. M8301) [27], $1 \mu$ of BactF upstream primer $(50 \mathrm{pmol} / \mu \mathrm{l}), 1 \mu \mathrm{l}$ of BactR downstream primer $(50 \mathrm{pmol} / \mu \mathrm{l})$, for Bacteroidetes detection or $1 \mu \mathrm{l}$ of FirmF upstream primer $(50 \mathrm{pmol} / \mu \mathrm{l})$, and $1 \mu \mathrm{l}$ of FirmR downstream primer $(50 \mathrm{pmol} / \mu \mathrm{l})$, for Firmicutes detection, and $4 \mu \mathrm{l}$ of dNTPs (10 mM each), and $24.5 \mu \mathrm{l}$ of DEPC-treated water. The PCR amplification profile was an initial denaturation step of $5 \mathrm{~min}$ at $95^{\circ} \mathrm{C}$ followed by 40 cycles of denaturation at $94^{\circ} \mathrm{C}$ for $45 \mathrm{~s}$, annealing at $62^{\circ} \mathrm{C}$ for $45 \mathrm{~s}$ (for Bacteroidetes amplification), while the annealing was $58^{\circ} \mathrm{C}$ at $45 \mathrm{~s}$ (for Firmicutes amplification), and extension at $72^{\circ} \mathrm{C}$ for $1.5 \mathrm{~min}$, with a final extension step of $10 \mathrm{~min}$ at $72^{\circ} \mathrm{C}$. The PCR thermal cycling was done using a Biometra PCR system and the expected PCR product characteristic for Bacteroidetes was $396 \mathrm{bp}$ and that characteristic for Firmicutes was 161 bp.

\section{Gel electrophoresis}

The amplified PCR products were electrophoresed through $1.5 \%$ agarose gel in Tris acetate/EDTA (TAE) buffer by using $100 \mathrm{~V}$ for $1 \mathrm{~h}$, and the PCR product bands were visualized by staining with $0.01 \%$ ethidium bromide $(0.5 \mu \mathrm{g} / \mathrm{ml})$. Polymerase chain reaction product bands were visualized under
UV light using a UV transilluminator and photos were taken using a gel documentation system [28].

\section{Blood samples}

Five $\mathrm{ml}$ of blood were drawn from the antecubital vein under aseptic precautions from fasting (for 12$14 \mathrm{~h})$ subjects. After centrifugation serum was collected from each subject to evaluate inflammatory markers [hs-CRP, lipid profile (total cholesterol, HDL cholesterol, LDL cholesterol, triglyceride)]. 1 - lipid analysis: Lipid assays in sera were determined by chemistry analyzer Olympus AU 400. 2 - the serum hs-CRP assay was based on the chemiluminescence technique. Determination of hs-CRP concentrations was performed with the Diagnostic Products Immulite 2000 analyzer (Block Scientific, Nutley, NJ); assay limits ranged from below $0.1 \mathrm{mg} / \mathrm{l}$ to above $10.0 \mathrm{mg} / \mathrm{l}$.

\section{Statistical analysis}

Statistical analysis was performed using the software SPSS 12.0 (SPSS: Chicago, IL). Variables were expressed as mean \pm standard deviation (SD). Mean values were compared among subjects using Student's $t$ test and ANOVA was used to compare variables between all groups. For comparing categorical data, $\chi^{2}$ test was performed. The exact test was used instead when the expected frequency was less than 5. Spearman's correlation coefficient rho was used to correlate between nonnormally distributed continuous variables. A probability value ( $p$ value) less than 0.05 was considered statistically significant.

\section{Results}

The results of PCR product bands for Bacteroidetes and Firmicutes by the gel documentation system of some cases are shown in Figure 1. Distribution of Bacteroidetes and Firmicutes was significantly increased in the obese group compared to the normal weight group ( $p=0.003, p<0.001$ respectively) (Table I, II). Only 21 subjects had one positive bacteria (13 were positive for Firmicutes and 8 for Bacteroidetes). Table III shows the means and SDs of different variables and their statistical significance in both groups. Both cholesterol and hsCRP were significantly higher in obese individuals ( $p=0.03, p=0.05$ respectively). Table IV shows the cross-tabulation between Firmicutes and Bacteroidetes in children and adults. Firmicutes showed a statistically significant increase in the adult group $(p=0.031)$. As regards the results of dietary analysis, subjects were divided into low and high fat intake. According to carbohydrate intake they were divided into four groups. The fourth group had the highest carbohydrate intake. We could not correlate changes in gut microbiota with fat or 

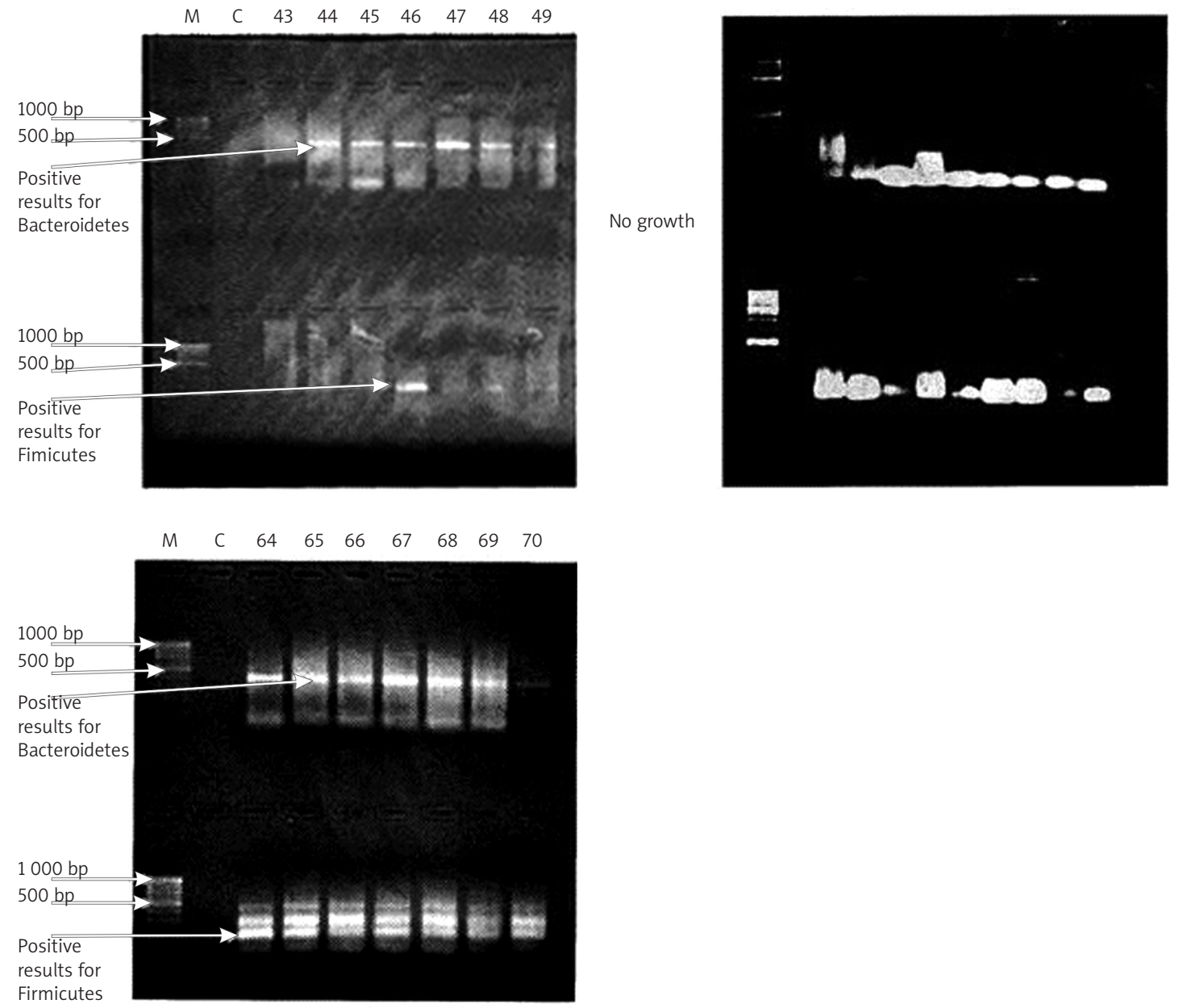

Figure 1. Results of the PCR product bands for Bacteroidetes and Firmicutes by gel documentation system of some cases

Table I. Distribution of Bacteroidetes and Firmicutes in obese and normal weight subjects

\begin{tabular}{|c|c|c|c|c|c|c|c|}
\hline & & \multicolumn{2}{|c|}{ Bacteroidetes } & \multirow[t]{2}{*}{ Total } & \multicolumn{2}{|c|}{ Firmicutes } & \multirow[t]{2}{*}{ Total } \\
\hline & & 1.00 & 2.00 & & 1.00 & 2.00 & \\
\hline \multirow[t]{2}{*}{ Obesity } & Count & 43 & 9 & 52 & 45 & 7 & 52 \\
\hline & $\%$ Within obesity & $82.7 \%$ & $17.3 \%$ & $100.0 \%$ & $86.5 \%$ & $13.5 \%$ & $100.0 \%$ \\
\hline \multirow{2}{*}{$\begin{array}{l}\text { Normal } \\
\text { weight } \\
\text { subjects }\end{array}$} & Count & 13 & 14 & 27 & 12 & 15 & 27 \\
\hline & $\begin{array}{c}\% \text { Within normal } \\
\text { weight }\end{array}$ & $48.1 \%$ & $51.9 \%$ & $100.0 \%$ & $44.4 \%$ & $55.6 \%$ & $100.0 \%$ \\
\hline
\end{tabular}

Table II. $\chi^{2}$ Tests for Bacteroidetes and Firmicutes in obese and normal weight subjects

\begin{tabular}{|c|c|c|c|c|c|c|}
\hline & $\begin{array}{l}\text { Asymp. sig. } \\
\text { (2-sided) }\end{array}$ & $\begin{array}{l}\text { Exact sig. } \\
\text { (2-sided) }\end{array}$ & $\begin{array}{l}\text { Exact sig. } \\
\text { (1-sided) }\end{array}$ & $\begin{array}{l}\text { Asymp. sig. } \\
\text { (2-sided) }\end{array}$ & $\begin{array}{l}\text { Exact sig. } \\
\text { (2-sided) }\end{array}$ & $\begin{array}{l}\text { Exact sig. } \\
\text { (1-sided) }\end{array}$ \\
\hline & \multicolumn{2}{|c|}{ Bacteroidetes } & \multicolumn{4}{|c|}{ Firmicutes } \\
\hline Pearson $\chi^{2}$ & 0.001 & & & $<0.001$ & & \\
\hline Continuity correction & 0.003 & & & $<0.001$ & & \\
\hline Likelihood ratio & 0.002 & & & $<0.001$ & & \\
\hline Fisher's exact test & & 0.003 & 0.002 & & $<0.001$ & $<0.001$ \\
\hline $\begin{array}{l}\text { Linear-by-linear } \\
\text { association }\end{array}$ & 0.001 & & & $<0.001$ & & \\
\hline $\mathrm{N}$ of valid cases & $<0.001$ & & & $<0.001$ & & \\
\hline
\end{tabular}


carbohydrate intake. Interestingly, the study found a trend for subjects with high fat intake to have positive Firmicutes, and those with the highest carbohydrate intake to have positive Bacteroidetes and Firmicutes (Figure 2). The study also showed a significant positive trend for higher hsCRP in subjects with positive Firmicutes $(p=0.004)$, as shown in Table V.

\section{Discussion}

Obesity is now characterized by a cluster of several metabolic disorders, and by low grade inflammation. The evidence that the gut microbiota composition can be different between healthy and obese and type 2 diabetic patients has led to the study of this environmental factor as a key link between the pathophysiology of metabolic diseases and the gut microbiota. Techniques based on the PCR are commonly used and provide rapid qualitative information on the composition of the intestinal microbiota [29]. Qualitative changes of the gut microbiota according to gender and species are well known and there are wide interpersonal variations in gut microbiota as a result of host genetic and environmental factors (e.g. mother's microbiota, birth place, diet, and living conditions). Our study revealed that the proportions of the phyla Firmicutes and Bacteroidetes were statistically significantly increased in the obese group compared to the normal weight group ( $p<0.001, p=0.003$ respectively). Results obtained in both rodents and humans suggest that obesity is associated with an altered composition of gut microbiota. Turnbaugh et al. (2009) observed wide shifts of the two major phyla: obese are characterized by more Firmicutes versus lean individuals; some authors show a drop in Bacteroidetes upon obesity [30], whereas other authors show no change or even an increase of Bacteroidetes in overweight [30-33]. This highlights the danger of generalizing observations of changes in microbiota composition from one population to another.

To date, 73 genomes of members of Firmicutes have been fully or partially sequenced. Interestingly, hydrogen-producing members of the family Prevotellaceae within the Bacteroidetes phylum, as well as certain Firmicutes, were more prominent in microbiota of obese individuals. This is believed to accelerate fermentation of otherwise indigestible carbohydrates, thereby leading to increased acetate production and subsequently higher energy absorption [34]. A question remains open: are the changes in gut microbiota in overweight or obese individuals due to the obesity per se, or due to changes in nutritional habits in obese people?

To explore the roles of diet on intestinal microbial ecology, dietary records were analysed for carbohydrate and fat contents. We could not correlate changes in gut microbiota with fat or carbohydrate intake. Interestingly, the study showed a trend for subjects with high fat intake to have positive Firmicutes, and those with the highest carbohydrate intake to have positive Bacteroidetes and Firmicutes. Other studies have correlated changes in gut microbiota with carbohydrate intake [35]. Data obtained in animals suggest that a high-fat diet - and not the obese state per se - can modulate microbiota composition towards an increase in Firmicutes and a proportional decrease in Bacteroidetes [36]. This highlights the likelihood

Table III. Comparison between the obese and normal weight groups

\begin{tabular}{|lcccc|}
\hline & Obesity & Mean & $\begin{array}{c}\text { Standard } \\
\text { deviation }\end{array}$ & $\begin{array}{c}\text { Sig. } \\
\text { (2-tailed) }\end{array}$ \\
\hline FBS & 1 & 93.07 & 21.82 & 0.426 \\
\cline { 2 - 5 } & 2 & 89.83 & 11.04 & 0.419 \\
\hline Cholesterol & 1 & 197.93 & 37.04 & 0.038 \\
\cline { 2 - 5 } & 2 & 180.91 & 34.65 & 0.037 \\
\hline Triglyceride & 1 & 112.31 & 38.68 & 0.127 \\
\cline { 2 - 5 } & 2 & 96.45 & 52.97 & 0.137 \\
\hline HDL & 1 & 41.11 & 8.16 & 0.624 \\
\hline LDL & 2 & 42.10 & 9.83 & 0.629 \\
\cline { 2 - 5 } & 2 & 131.76 & 37.81 & 0.143 \\
\hline HsCRP & 1 & 6.43 & 10.31 & 0.053 \\
\cline { 2 - 5 } & 2 & 2.35 & 3.31 & 0.036 \\
\hline BMI & 1 & 34.82 & 5.84 & 0.000 \\
\cline { 2 - 5 } & 2 & 21.85 & 2.66 & 0.000 \\
\hline
\end{tabular}

1 - obese group, 2 - normal weight group

FBS - fasting blood glucose, $H D L$ - high density lipoprotein, $L D L$-low density lipoprotein, HSCRP - high-sensitivity C-reactive protein, $B M I-$ body mass index, ${ }^{*} p$ is significant $<0.05$

Table IV. Firmicutes and Bacteroidetes in children and adults

\begin{tabular}{|c|c|c|c|c|c|c|c|c|}
\hline & & & \multicolumn{2}{|c|}{ Firmicutes } & \multirow[t]{2}{*}{ Total } & \multicolumn{2}{|c|}{ Bacteroidetes } & \multirow[t]{2}{*}{ Total } \\
\hline & & & 1 (+ve) & $2(-v e)$ & & 1 (+ve) & 2 (-ve) & \\
\hline \multirow[t]{4}{*}{ Age group } & 1 - children & Count & 22 & 18 & 40 & 27 & 13 & 40 \\
\hline & & $\%$ Within age & $55.0 \%$ & $45.0 \%$ & $100.0 \%$ & $67.5 \%$ & $32.5 \%$ & $100.0 \%$ \\
\hline & 2 - adults & Count & 31 & 8 & 39 & 29 & 10 & 39 \\
\hline & Adult & $\%$ Within age & $79.5 \%$ & $20.5 \%$ & $100.0 \%$ & $74.4 \%$ & $25.6 \%$ & $100.0 \%$ \\
\hline
\end{tabular}



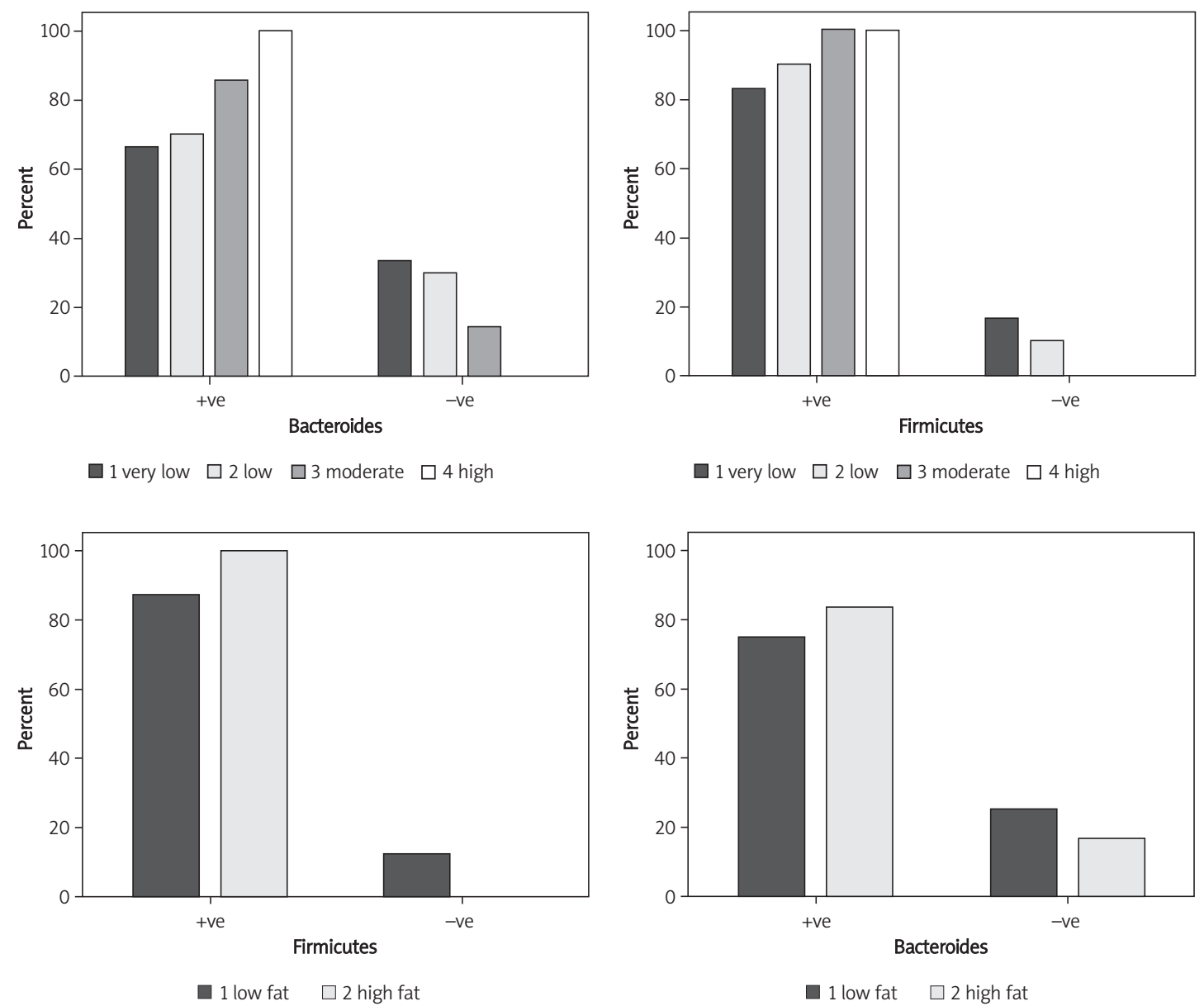

Figure 2. Relation between Firmicutes and Bacteroides and fat or carbohydrates intake

Table V. HsCRP in positive and negative Firmicutes and Bacteroidetes subjects

\begin{tabular}{|lccccc|}
\hline & HsCRP & $N$ & Mean [mg/l] & Standard deviation & Sig. (2-tailed) \\
\hline Firmicutes & -ve & 11 & 1.3745 & 1.12117 & 0.004 \\
\cline { 2 - 6 } & +ve & 50 & 5.3426 & 4.91056 & \\
\hline Bacteroidetes & -ve & 14 & 4.0264 & 8.02824 & 0.759 \\
\cline { 2 - 6 } & +ve & 47 & 4.8060 & 8.28610 & \\
\hline
\end{tabular}

of external factors such as diet, and potentially host factors, in modulating the microbiota.

Another point remains to be elucidated: could we attribute the low grade inflammatory process observed in obese subjects to changes in the gut bacteria? Our study showed that hsCRP was significantly higher in obese individuals $(p=0.05)$. The study also showed a significant positive trend for higher hsCRP in subjects with positive Firmicutes $(p=0.004)$. The role of the gut microbiota in modulation of plasma lipopolysaccharide (LPS) levels, which triggers the inflammatory tone and the onset of obesity, might be possible. Cani et al. (2007) have shown that subcutaneous infusion of LPS can cause weight gain and insulin resistance in mice without altering energy intake [37]. In accor- dance with this, mice lacking Toll-like receptor 4 (TLR4), which recognizes LPS, are resistant to dietinduced obesity and insulin resistance [38].

In conclusion, our data support the key idea that the gut microbiota can contribute to the pathophysiology of obesity. This could be considered when developing strategies to control obesity and its associated diseases by modifying the gut microbiota.

\section{References}

1. World Health Organization. The world health report 2002. Reducing risks, promoting healthy life. WHO, Geneva 2002.

2. Olshansky SJ, Passaro DJ, Hershow RC, et al. A potential decline in life expectancy in the United States in the 21st century. N Engl J Med 2005; 352: 1138-45. 
3. Vishal S, Faheem A, Chul W, et al. Impact of morbid obesity on pulmonary function. Arch Med Sci 2008; 4: 66-70.

4. Flint HJ, Bayer EA, Lamed R, White BA. Polysaccharide utilization by gut bacteria: potential for new insights from genomic analysis. Nature Rev Microbiol 2008; 6: 121-31.

5. Gordon S. Microbial ecology: human gut microbes associated with obesity. Nature 2006; 444: 1022-23.

6. Turnbaugh PJ, Ley RE, Mahowald MA, Magrini V, Mardis $E R$, Gordon JI. An obesity associated gut microbiome with increased capacity for energy harvest. Nature 2006; 444 : 1027-31.

7. Backhed F, Manchester JK, Semenkovich CF, Gordon JI. Mechanisms underlying the resistance to diet-induced obesity in germ-free mice. Proc Natl Acad Sci USA 2007; 104: 979-84.

8. Backhed F, Ley RE, Sonnenburg JL, Peterson DA, Gordon $J$ I. Host-bacterial mutualism in the human intestine. Science 2005; 30: 1915-20.

9. Xu J, Mahowald MA, Ley RE, et al. Evolution of symbiotic bacteria in the distal human intestine. PLoS Biol 2007; 5: e156.

10. Xu J, Gordon JI. Inaugural article: Honor thy symbionts. Proc Natl Acad Sci USA 2003; 100: 10452-9.

11. Eckburg PB, Bik EM, Bernstein CN, et al. Diversity of the human intestinal microbial flora. Science 2005; 308: 1635-38.

12. Lay C, Doré J, Rigottier-Gois L. Separation of bacteria of the Clostridium leptum subgroup from the human colonic microbiota by fluorescence-activated cell sorting or groupspecific PCR using 16S rRNA gene oligonucleotides. FEMS Microbiol Ecol 2007; 60: 513-20.

13. Zoetendal E, Vaughan E, de Vos W. The microbial world within us. Mol Microbiol 2006; 59: 1639-50.

14. Ley RE, Bäckhed F, Peter T, Lozupone CA, Knightand RD. Obesity alters gut microbial ecology. PNAS 2005; 102: 11070-5.

15. Batra A, Pietsch J, Fedke I, et al. Leptin-dependent Toll like receptor expression and responsiveness in preadipocytes and adipocytes. Am J Pathol 2007; 170: 1931-41.

16. Tsukumo DM, Carvalho-Filho MA, Carvalheira JBC, et al. Loss-of-function mutation in Toll-like receptor 4 prevents diet-induced obesity and insulin resistance. Diabetes 2007; 56: 1986-98.

17. Cani PD, Neyrinck AM, Fava F, et al. Selective increases of bifidobacteria in gut microflora improve high-fat-diet induced diabetes in mice through a mechanism associated with endotoxaemia. Diabetologia 2007; 50: 2374-83.

18. Siebler J, Galle PR, Weber MM. The gut-liver-axis: endotoxemia, inflammation, insulin resistance and NASH. J Hepatol 2008; 48: 1032-34.

19. Cani PD, Bibiloni R, Knauf C, et al. Changes in gut microbiota control metabolic endotoxemia-induced inflammation in high-fat diet-induced obesity and diabetes in mice. Diabetes 2008; 57: 1470-81.

20. Rubins HB, Robins SJ, Collins D, et al. Gemfibrozil for the secondary prevention of coronary heart disease in men with low levels of high-density lipoprotein cholesterol. Veterans Affairs High-Density Lipoprotein Cholesterol Intervention Trial Study Group. N Engl J Med 1999; 341: 410 .

21. van Guldener C, Stam F, Stehouwer CD. Homocysteine metabolism in renal failure. Kidney Int 2001; 59: S234.

22. Bostom AG, Bausserman L, Jacques PF, et al. Cystatin C as a determinant of fasting plasma total homocysteine levels in coronary artery disease patients with normal serum creatinine. Arterioscler Thromb Vasc Biol 1999; 19: 2241.

23. Cani PD, Delzenne NM, Amar J, Burcelin R. Role of gut microflora in the development of obesity and insulin resistance following high-fat diet feeding. Pathologie Biologie 2008; 56: 305-9.

24. Obesity: preventing and managing the global epidemic. Report of a WHO consultation. World Health Organization. Technical Report Series 2000; 894: 250-3.

25. Alexandra JS, Laura LP, Bo Wei, et al. Abundant and diverse fungal microbiota in the murine intestine. Appl Environ Microbiol 2006; 72: 793-801.

26. Jonathan B, James B. Abundant and diverse fungal microbiota in the murine intestine. Appl Environ Microbiol 2006; 1: 793-801.

27. Dick LK, Field KG. Rapid estimation of numbers of fecal Bacteroidetes by use of a quantitative PCR assay for $16 \mathrm{~S}$ rRNA genes. Appl Environ Microbiol 2004; 70: 5695-7.

28. Bernhard AE, Field KG. Identification of nonpoint sources of fecal pollution in coastal waters by using host-specific $16 \mathrm{~S}$ ribosomal DNA genetic markers from fecal anaerobes. Appl Environ Microbiol 2000; 66: 1587-94.

29. Huijsdens XW, Linskens RK, Mak M, et al. Quantification of bacteria adherent to gastrointestinal mucosa by realtime PCR. J Clin Microbiol 2002; 40: 4423-7.

30. Turnbaugh PJ, Micah $\mathrm{H}$, Tanya $\mathrm{Y}$, et al. A core gut microbiome in obese and lean twins. Nature 2008; 457: 480-4 .

31. Carmen C, Muriel D, Erika I, et al. Intestinal integrity and Akkermansia muciniphila, a Mucin-degrading member of the intestinal microbiota present in infants, adults, and the elderly. Appl Envir Microbiol 2007; 73: 7767-70.

32. Duncan SH, Lobley GE, Holtrop G, et al. Human colonic microbiota associated with diet, obesity and weight loss. Int J Obes 2008; 32: 1720-4.

33. Ley RE, Turnbaugh PJ, Jeffrey SK, Gordon I. Microbial ecology: human gut microbes associated with obesity. Nature 2006; 444: 1022-3.

34. Zhang H, DiBaise JK, Zuccolo A. Human gut microbiota in obesity and after gastric bypass. Proc Natl Acad Sci U S A 2009; 106: 2365-70.

35. Ley RE. Obesity and the human microbiome. Curr Opin Gastroenterol 2010; 26: 5-11

36. Hildebrandt MA, Hoffman C, Sherrill-Mix SA, et al. High fat diet determines the composition of the murine gut microbiome independently of obesity. Gastroenterology 2009; 137: 1716-24.

37. Cani PD, Amar J, Iglesias MA, et al. Metabolic endotoxemia initiates obesity and insulin resistance. Diabetes 2007; 56: 1761-72.

38. Tsukumo D, Carvalho-Filho M, Carvalheira J, et al. Lossof-function mutation in Toll-like receptor 4 prevents dietinduced obesity and insulin resistance. Diabetes 2007; 56: 1886-98. 